\title{
Research Article \\ Research on the Safety Audit Methods for Two-Lane Highway Based on HRV
}

\author{
Zhan-dong Zhu, ${ }^{1}$ Ying-chih Lu, ${ }^{1}$ Cheng-hong Fu, ${ }^{1}$ and Ting $X u^{2}$ \\ ${ }^{1}$ Department of Transportation, Fujian University of Technology, Fuzhou 350108, China \\ ${ }^{2}$ School of Automobile, Chang'an University, Xian 710064, China \\ Correspondence should be addressed to Zhan-dong Zhu; zhuzhandong@emails.bjut.edu.cn
}

Received 15 November 2013; Revised 13 February 2014; Accepted 4 March 2014; Published 31 March 2014

Academic Editor: Wuhong Wang

Copyright (C) 2014 Zhan-dong Zhu et al. This is an open access article distributed under the Creative Commons Attribution License, which permits unrestricted use, distribution, and reproduction in any medium, provided the original work is properly cited.

\begin{abstract}
In order to explore stable route safety evaluation indicators, this study discusses the relationship between the heart rate variability (HRV) and other factors, such as design speed, operating speed, acceleration rate, and velocity gradient through a lot of experiments. The results show that operating speed coordination and velocity gradient $\left(G_{v}\right)$ outperform others as road safety indicators. Speed coordination evaluation criteria: $\left|\Delta V_{85}\right| \leq 10 \mathrm{~km} / \mathrm{h}$, good coordination; $10 \mathrm{~km} / \mathrm{h} \leq\left|\Delta V_{85}\right| \leq 20 \mathrm{~km} / \mathrm{h}$, general coordination, route indicators of adjacent sections should be adjusted, so that the speed difference is not more than $10 \mathrm{~km} / \mathrm{h} ;\left|\Delta V_{85}\right| \geq 20 \mathrm{~km} / \mathrm{h}$, poor speed coordination, it needs to readjust the design of the adjacent sections. Speed gradient evaluation criteria: $G_{v} \leq 0.10$, good road safety; $0.10 \leq G_{v}<0.15$, common road safety; $G_{v}>0.15$, poor road safety and the adjacent sections need to readjust. The conclusions provide the theoretical reference for highway safety evaluation.
\end{abstract}

\section{Introduction}

In order to improve road safety, research abroad explored the relationship between speed statistics and accident rate. Kloeden et al. studied the country road (or national highway) and concluded that the decline of the average speed rather than the decline of velocity gradient contributes to traffic safety [1]. Garber and Gadiraju concluded that the accident rate is proportional to the variation of velocity which increases as the accident rate increases [2]. However, Lassarre in France concluded that the influence of velocity variance on the safety is not significant [3]. Lave found that the influence of velocity variance on accident rate is more significant than that of average velocity [4]. Baruya and Finch studied the relationship between average velocity, velocity gradient, and personal injury accidents and found that average velocity and velocity gradient greatly affect the accident rate [5]. Although the findings discussed above are not consistent and sometimes even contradictory, they indicate that the relationship among average velocity, velocity gradient, and velocity variance to accident rate remains uncertain.

In China, many research results have the same characteristic, which are trying to establish the relationship between speed and accident number. Unfortunately, the traffic accident data in China was kept by the police departments, so it is not easy to obtain original accident data. Even if accident data can be gained, it cannot meet needs of research. The data from the traffic police department on the cause of the accident, morphology, and classification are not the same with the researchers, that is, not consistent with standard statistical accident. In addition, in recent years, China is in the large-scale construction period, and the roads expansions are very frequent, resulting in shorter service life of road and the lack of stable long-term accident statistics. So the convincing results are scarce, and it is difficult to evaluate the safety of a new road.

Considering the above issues, this study investigates the relationship between road safety and speed statistics, with physiological aspects on drivers through a series of experiments.

\section{Materials and Methods}

A transportation network consists of human beings, vehicles, roads, and traffic control devices. Any change of these factors 
will affect drivers' reactions. While the external reaction may be observed by abnormal driving behavior (such as acceleration), the inner one appears in driver's psychological changes (such as HRV). Therefore, the studies on road safety associated with driving psychological changes become popular in recent years.

Brookhuis and de Waard studied the relation between the driver's psychological pressures and ECG and EEG changes, respectively, in the crowded city ring Expressway and the free flow of Expressway and concluded that psychological pressure can be obtained in the ECG and EEG responses $[6,7]$. Pan studied the relationship among drivers' heart rate, blood pressure, and radius of horizontal curve, curve length, curve angle, and so forth in the mountain road test road in a certain speed $[8,9]$. Qiao studied the key parameters of the two-lane highway in mountainous area based on driver factor analysis (parameters of what) and put forward the design parameters to enable driving comfortably on twolane highway in mountainous area [10]. Related literatures selected the changes of the driver real-time heart rate variability, namely, HRV to indicate workload of the drivers and divided its threshold [11-15]. HRV is a balanced and effective detection index between the characterization of sympathetic and vague nerves, measures the continuous sinus heartbeat interval (instantaneous heart rate) of the tiny fluctuations of ECG changes, and is more sensitive to describe physiological index of the driver $[16,17]$. Wang et al. proposed a composite measure consisting of three physiological measures, facial skin temperature, eye blinks, and pupil dilation [18]. J. Lee and S. Lee develop a model for evaluation of highway alignment design with a new evaluation index as vehicle spacing [19]. The above literatures studied the traffic safety problems based on EEG and ECG reactions of the drivers, and conclusions show that there was some relationship between the driver's physiological reactions and traffic safety and route parameter.

Because the experiments were all drawn in the fields, taking into account that the EEG anti-interference ability was poor, the heart rate variability (HRV) was chosen as the index. The experiments were drawn to study the stable and reliable relationship between the driver of HRV and different safety evaluation index of the road. Combination of all researches and road safety evaluation indicators include speed consistency, speed coordination, speed reduction coefficient, and speed gradient.

2.1. Data Collection. The devices for the experiments include a test vehicle, high precision GPS, KF2 dynamic multiple physiological parameters detection apparatus (KF2), and a camera. The test vehicle is Santana 2000, and the high precision GPS instrument selected Novatel dynamic GPS to acquire speed change and coordinate continuous velocity and acceleration and other related indicators, corresponding to the road alignment. KF2 dynamic multiple physiological parameters detection can obtain the drivers' HRV indicator at any time, and road traffic environment is recorded by camera, and manual recording special conditions and data processing should be removed without the free-flow speed data. Test sections selected two-lane highways in Jiangxi

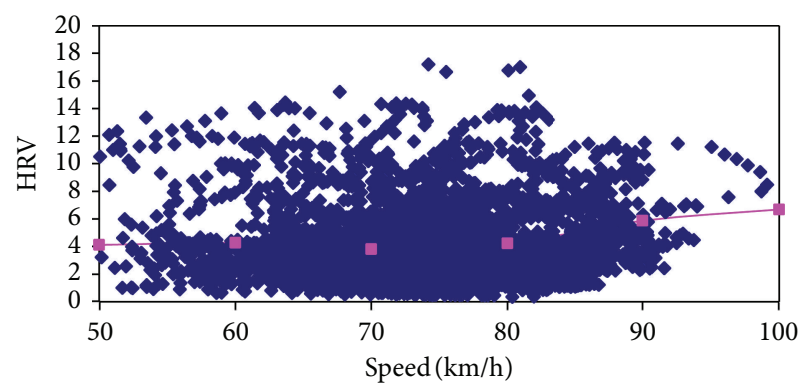

FIgURE 1: Speed versus heart rate variability.

Yichun Anfu, Xinjiang Kuitun-Karamay, Xinjiang alar-hotan, and Xinjiang Akesu-Kuche. Yichun Anfu section is located in the mountainous area, and the remaining roads are in plain area. The total mileage of test sections is about $800 \mathrm{~km}$. The sample size of each type is greater than 50 .

At the beginning of experiments, the basic information of drivers, the installation of test equipment, including KF2, GPS, and camera, and the time of opening KF2 should be recorded. After installing the device, drivers were required to obtain a calm state. Then the driver drove on the test section and turned on the GPS and camera to record driving conditions and road traffic environment until the end of the test. The records should be marked for the special moments point and the traffic environment change time point (section) for further data processing. In order to eliminate noises, data for 3 minutes before and after tests are excluded.

\subsection{Relationship between Road Safety \\ Evaluation Indicators and HRV}

2.2.1. Design Speed Consistency and HRV. At present in the routine design, design speed is still selected as the control index in China. For the same type highways of terrain, the design speed is a constant value. For example, on two-lane highways in plain areas, it needs to use the design speed of $80 \mathrm{~km} / \mathrm{h}$, and $60 \mathrm{~km} / \mathrm{h}$ in the mountainous areas. The benefits of design speed concept are easy to use. According to the "Guidelines for Safety Audit of Highway," design speed consistency is defined as the absolute value of the difference between the operating speed and design speed. Figure 1 shows a scatter plot between the speed and the driver of HRV test vehicle in two-lane highway.

In Figure 1, design speed increasing, namely, the design speed consistency increasing, the drivers' HRV trend is not obvious, and the distribution range has no significant diffusion difference. There is not a similar trend between design speed consistency and HRV did not show an obvious consistent trend. It is concluded from psychological results that it is not inappropriate to select design speed consistency as a road safety evaluation index. Drivers tends to prefer a higher operating speed because of a better roadway alignment, while poor road alignment forces drive at lower speed, and only in poor route linear design speed will play a role. The minimum value, in the route design specifications only limits the design standard for the most unfavorable 


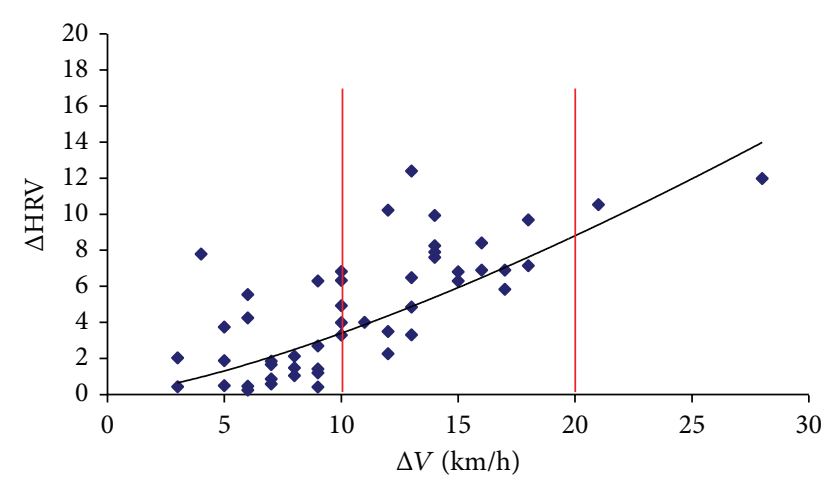

FIGURE 2: Operating speed coordination versus $\Delta \mathrm{HRV}$.

situation. For two-lane highways of the western plains region, average speed of good road sections is much higher than the design speed. The increase of speed consistency does not bring a corresponding increase in the accident rates. It is also the same in some foreign speed limit sections. From the experimental results it is illustrated that it is not appropriate to choose the design speed consistency to measure road safety.

\subsubsection{Operating Speed Coordination and HRV. The operating} speed coordination is the absolute value of the operating speed difference between adjacent sections. The sections are divided and grouped according to the different design elements within the section. Firstly nonfree flow data is removed. Then the whole road is divided into small sections as the straight section of the circular curve sections, longitudinal slope sections, and curved section in accordance with the Guideline. Sections with various features are found out and the corresponding speed value at the right time is selected from GPS. Thirdly, the operating speed coordination is calculated by speed difference between the adjacent sections. HRV data is obtained by KF2 from physiological indicators of the corresponding time. $\Delta \mathrm{HRV}$ and the $\Delta V$ data are then obtained. $\Delta V$ is the operating speed difference between the adjacent sections and $\triangle H R V$ is the HRV difference between the adjacent sections. The relationship between operating speed coordination and $\triangle \mathrm{HRV}$ is shown as Figure 2.

In Figure 2, $\triangle \mathrm{HRV}$ increases significantly when the operating speed coordination is increasing. When operating speed coordination is less than $10 \mathrm{~km} / \mathrm{h}$, the average value of $\triangle \mathrm{HRV}$ is about three. When operating speed coordination is enlarged to $10-20 \mathrm{~km} / \mathrm{h}$, the average $\Delta H R V$ grows up to about 7. And when operating speed coordination expanded to more than $20 \mathrm{~km} / \mathrm{h}$, HRV values are all greater than 10 . Results show that the speed of coordination is directly proportional to $\triangle \mathrm{HRV}$.

During the driving process, changes of adjacent operating speed will lead to the change of HRV, and especially the dramatic change of adjacent running speed can cause strong reaction of drivers' psychology. Therefore it is appropriate to select the operating speed coordination to measure the safety of the highway and it is also secure to select $20 \mathrm{~km} / \mathrm{h}$ as an evaluation threshold in the Guideline.
2.2.3. Speed Reduction Coefficient and HRV. Drivers will change acceleration or deceleration transformation according to the environment and road conditions during the running. According to statistics, the speed acceleration of the vehicle in the process of smooth driving generally remains between -0.15 and $0.15 \mathrm{~m} / \mathrm{s}^{2}$. If the speed acceleration is due to good traffic environment and roadway conditions, it is usually considered to be a safe behavior. In contrast, deceleration process, in particular severe deceleration, is often considered to be not safe. It means that a sudden change of road conditions occurs, and if the deceleration behavior cannot meet the road traffic needs, traffic accidents will occur. The statistics results show that traffic accidents account for a large proportion of accidents. Removing the nonfree-flow speed data, figuring out the speed and acceleration in the process of moving test vehicle, relationship between the acceleration and deceleration acceleration and $\mathrm{HRV}$ is analyzed, respectively. And the results are shown in Figure 3.

Derived from Figure 3, in the process of acceleration (Figure 3(a)), there is little correlation between the driver HRV and the acceleration of the vehicle. As the acceleration increases, HRV does not change significantly, reflecting the smaller driver psychological changes. It follows that the acceleration process is safe. This is consistent with the conclusion of the above analysis. In the process of deceleration (Figure 3(b)), as the acceleration increases, HRV also increases rapidly. When the acceleration is greater than $1.5 \mathrm{~m} / \mathrm{s}^{2}$ changes in HRV will be more intense, reflecting that the sudden deceleration behavior can result in strong psychological reaction. And the conclusion is consistent; namely, the deceleration process especially the sudden deceleration process is insecure.

During acceleration, the acceleration value of the driver is generally less than $1.0 \mathrm{~m} / \mathrm{s}^{2}$, and the maximum acceleration is up to $1.5 \mathrm{~m} / \mathrm{s}^{2}$. But during deceleration process, the acceleration value of the driver is generally below $1.5 \mathrm{~m} / \mathrm{s}^{2}$, and the maximum acceleration is about $2.5 \mathrm{~m} / \mathrm{s}^{2}$. It shows that the response of drivers' deceleration is bigger than that of acceleration. In the course of the research on deceleration, according to Moscow State University conclusions, the acceleration process is divided into the three intervals $0-0.5 \mathrm{~m} / \mathrm{s}^{2}, 0.5-1.5 \mathrm{~m} / \mathrm{s}^{2}$, and $1.5-2.5 \mathrm{~m} / \mathrm{s}^{2}$. The relationship between speed reduction coefficient and the accident rate was studied in the three cases, and we came to the conclusion that safety would be greatly reduced when the acceleration was more than $1.5 \mathrm{~m} / \mathrm{s}^{2}$. Deceleration greater than $1.5 \mathrm{~m} / \mathrm{s}^{2}$ is defined as the sudden deceleration behavior, and is often caused due to sudden changes in the road. It is very unsafe.

Choosing adjacent sections in which deceleration is greater than $1.5 \mathrm{~m} / \mathrm{s}^{2}$, and figuring out the speed reduction coefficient (the speed difference between first section and the latter sections and its own ratio), get the relationship between speed reduction coefficient and HRV, as shown in Figure 4. From the diagram, HRV increases with speed reduction coefficient increasing. When the speed reduction coefficient is more than 0.25 , which is the speed of a sudden decrease of more than $25 \%$, HRV changes rapidly. 


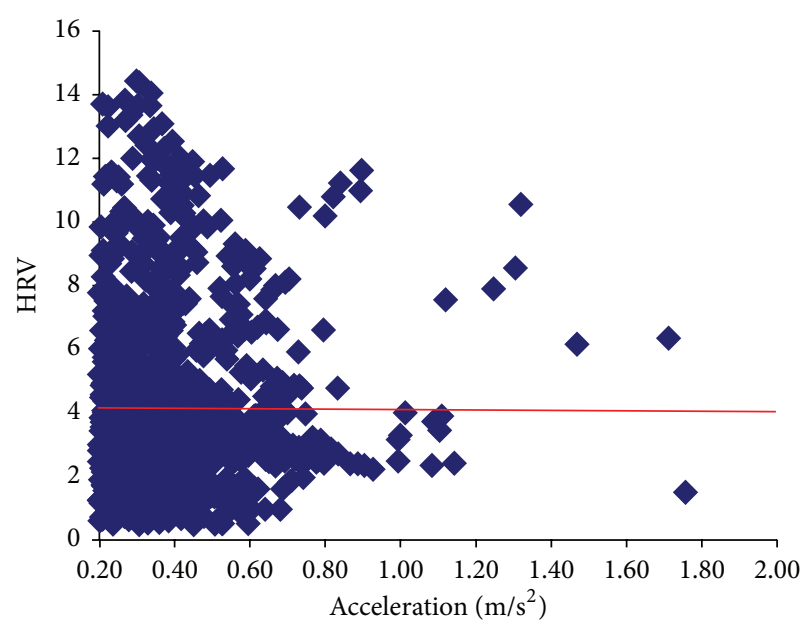

(a)

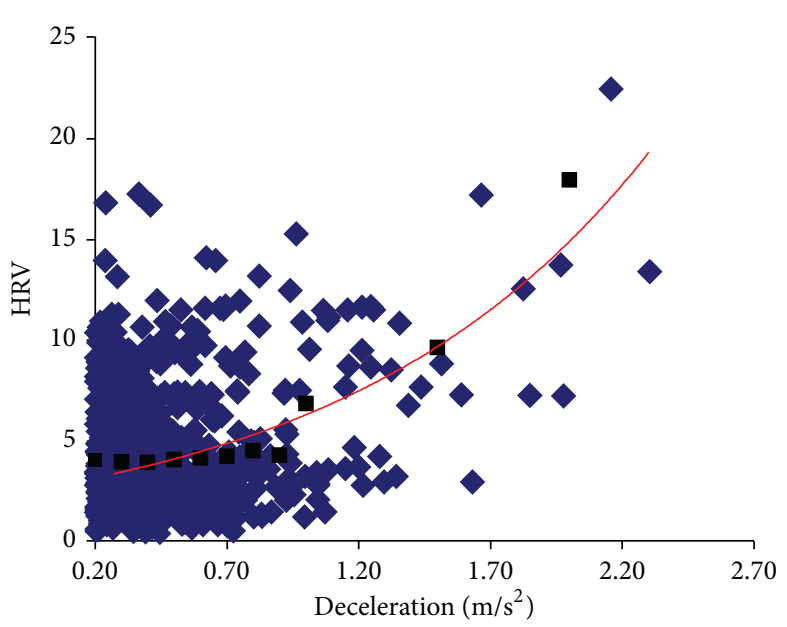

(b)

FIGURE 3: Relation between acceleration and HRV.

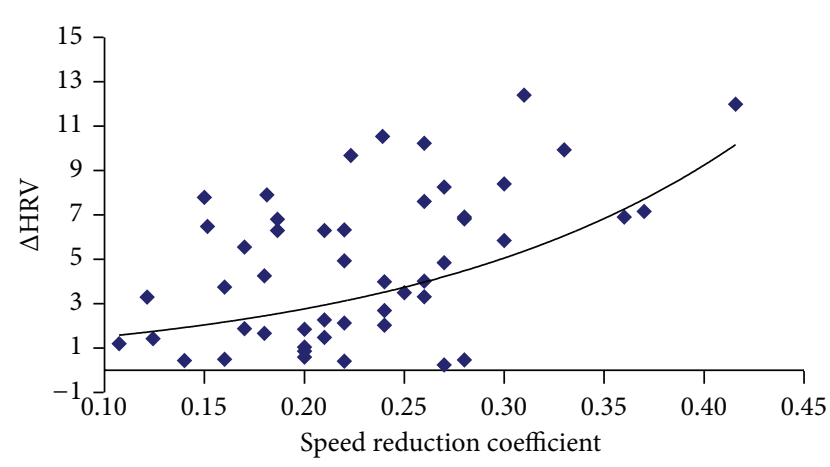

FIGURE 4: Relation between speed reduction coefficient and $\Delta$ HRV.

From Figure 4, it is concluded that it is appropriate to measure road safety with speed reduction coefficient. Because trend of HRV is more obvious when speed reduction coefficient of the adjacent sections is more than 0.25 , and then 0.25 is selected as the critical value (threshold) of the speed coefficient. Compared to the speed at the feature points of previous sections, if the speed coefficient of the latter section reduced more than 0.25 , it is considered that the routine design has potential security risks and needs to be improved.

2.2.4. Speed Gradient and HRV. The above analysis shows that operating speed coordination and speed reduction coefficient are closely related with the change of driver's HRV. Both indicators can be measured by the amount of change in operating speed of adjacent sections; the two conclusions are certainly consistent. However, there exists a common defect that they cannot measure how much operating speed changes in alignment curve in unit length sections.

For example, a straight section is followed by a circular curve segment and roads operating speed difference is $15 \mathrm{~km} / \mathrm{h}$. the psychological reactions of the driver are different on different lengths of the curve. For drivers, the 100 -meter radius circular curve may lead to a decline at a

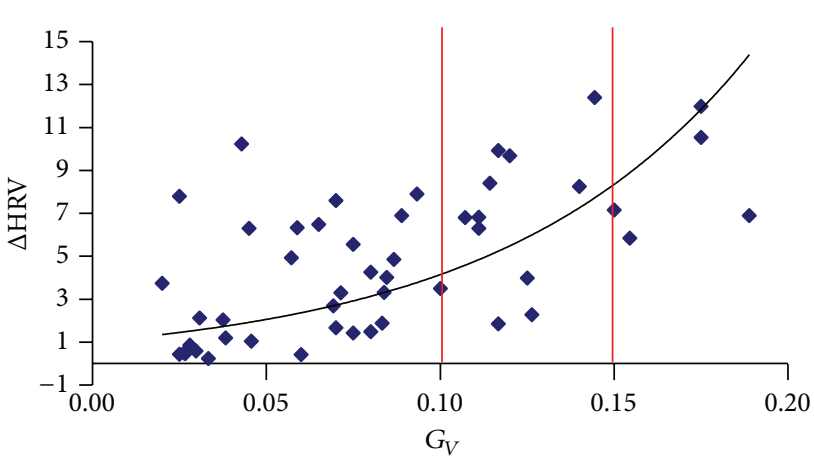

FIGURE 5: Relation between speed gradient and HRV.

dramatic rate and a 300-meter radius circular curve may lead to a slower decrease. Although two sections from the coordination of all belong to the general safety section, the previous is clearly larger than the latter on the driver's sudden reaction reflection. Therefore, an index named speed gradient is constructed to describe the above differences as follows:

$$
G_{v}=2 \times \frac{\Delta V_{85}}{L}
$$

where $G_{v}$ is the speed gradient; $L$ is curve length, assuming that the deceleration of the vehicle completes in the first half of the curve.

After removing non free-flow data, deceleration speed, which is used to study the relationship between speed gradient and HRV, is calculated by speed of adjacent sections. Statistical analysis is shown as in Figure 5.

It can be obtained from Figure 5 that as the velocity gradient increases, HRV is also gradually increasing, and both approximate logarithmic. When the speed gradient is less than 0.1, HRV growth trend is more gentle; when the speed gradient is over 0.10 , HRV increasing trend has accelerated very fast; and when the velocity gradient exceeds 0.15 , HRV increasing trend is very fast, reflecting strong 
psychological reactions of drivers. It shows that there is a strong correlation between the velocity gradient changes and changes of HRV.

\section{Results and Discussion}

It can be concluded from the above analysis that the changes in speed gradient and HRV are closely related and HRV increases as speed gradient increases. Speed gradient can be divided into three intervals: less than $0.10,0.10 \sim 0.15$, and more than 0.15 , three security descending order. And greater than 0.15 speed gradients in the design should be avoided.

In summary, correlation is not strong between design speed consistency and HRV. From the point of view of drivers' physiological responses, it is not suitable to be regarded as a safety evaluation indicator; speed coordination is closely correlated with HRV. $20 \mathrm{~km} / \mathrm{h}$ as the critical threshold of safety evaluation is also appropriate, and guideline about the speed coordination regulation is reasonable. During the deceleration of the vehicle, the speed reduction coefficient and the deceleration of the adjacent sections and the security have close relationship. Speed reduction coefficient is more than 0.25 and the deceleration greater than $1.5 \mathrm{~m} / \mathrm{s}^{2}$ is considered a potential safety risk; velocity gradient and HRV changes are closely related. According to the analysis the speed gradient should be divided into three groups as less than $0.10,0.10-0.15$, and more than 0.15 , and the speed gradient of greater than 0.15 in the design should be avoided.

Because the speed reduction coefficient and operating speed coordination are similar, in order to maintain consistency with the guideline, operating speed coordination is chosen as one audit index. The speed gradient measures road safety from the aspects of unit length of road section, avoiding the defect that operating speed coordination is the unique index. In general, the speed coordination measures the speed variation amplitude of adjacent sections, and the speed gradient measures how fast of the change of the adjacent section, which can be used in combination to evaluate the safety of route.

Operating speed coordination $\left|\Delta V_{85}\right|$ is the speed difference of adjacent sections. Speed coordination $\left|\Delta V_{85}\right|$ is evaluation standard: when $\left|\Delta V_{85}\right| \leq 10 \mathrm{~km} / \mathrm{h}$, good route design; $10 \mathrm{~km} / \mathrm{h}<\left|\Delta V_{85}\right|<20 \mathrm{~km} / \mathrm{h}$, common route design, when conditions permit, adjacent sections of technical indicators should be appropriately adjusted, in the condition that the operating speed difference is less than or equal to $10 \mathrm{~km} / \mathrm{h}$; $\left|\Delta V_{85}\right| \geq 20 \mathrm{~km} / \mathrm{h}$ means bad route design and the design of adjacent sections need to be adjusted.

The speed gradient evaluation standard: when $G_{v} \leq$ 0.10 , road safety is good; $0.10 \leq G_{v}<0.15$, road safety is common, when conditions permit adjacent sections of technical indicators should be appropriately adjusted; $G_{v}>$ 0.15 , road safety is poor and route indicator of adjacent sections need to be adjusted.

\section{Conclusions}

The paper studied the relationship among drivers heart rate variability of the vehicle in the running process and design speed consistency, operating speed coordination, speed reduction coefficient, and speed gradient. Then their relationship with safety is obtained from speed statistics. From analysis, operating speed coordination and the speed gradient can be chosen as indicators to measure traffic security. Conclusion provides a strong theoretical support for road safety evaluation.

\section{Conflict of Interests}

The authors declared that they have no conflicts of interests to this work.

\section{Acknowledgments}

The project is supported by National Natural Science Foundation of China (no. 51308058) and China Postdoctoral Science Foundation (no. 2013M532007).

\section{References}

[1] C. N. Kloeden, G. Ponte, and A. J. McLean, “Traveling speed and the risk of crash involvement on rural roads," Road Accident Research Unit CR 204, Adelaide University, 2003.

[2] N. J. Garber and R. Gadiraju, "Factors affecting speed variance and its influence on accidents," Transportation Research Record, vol. 1213, pp. 64-71, 1989.

[3] S. Lassarre, "The introduction of the variables traffic volume, speed, and belt-wearing into a predictive model of the severity of accidents," Accident Analysis and Prevention, vol. 18, no. 2, pp. 129-134, 1996.

[4] C. Lave, "Speeding, coordination, and the 55-mph limit," The American Economic Review, vol. 75, no. 5, pp. 1160-1164, 1985.

[5] A. Baruya and D. J. Finch, "Investigation of traffic speeds and accidents on urban roads," in PTRC European Transport Forum, pp. 219-230, University of Warwich, 1994.

[6] K. A. Brookhuis and D. de Waard, "The use of psychophysiology to assess driver status," Ergonomics, vol. 36, no. 9, pp. 1099-1108, 1993.

[7] R. Inoue, "Safety measures against construction accidents in kanto regional development bureau," Public Works Management Journal, pp. 9-12, 2002.

[8] X.-D. Pan, Application of Human Information Technology in Road Safety Evaluation of Geometric Structure, Transportation College of Tongji University, 2002.

[9] S. Cafiso, G. La Cava, and A. Montella, "Safety index for evaluation of two-lane rural highways," Transportation Research Record, vol. 2019, pp. 136-145, 2007.

[10] J.-G. Qiao, Study on the Key Parameter of Two-Lane Highway in Mountain Area Based on Driver's Factors, The College of Architecture and Civil Engineering, Beijing University of Technology, 2006.

[11] R. Bird and I. Hashim, "Exploring the relationship between safety and the Consistency of geometry and speed on British Roads," in Proceedings of the 85th Annual Meeting Compendium of Papers, Transportation Research Board, National Research Council, 2006.

[12] D. H. Harwood, F. M. Council, E. Hauer, W. E. Hughes, and A. Vogt, "Prediction of the expected safety performances of 
the rural two-lane highways," Federal Highway Administration, U.S. Department of Transportation RD-99-207, 2000.

[13] X. Cao, Study on the Highway Longitudinal Alignment Safety Evaluation Based on Drivers Workload, The College of Architecture and Civil Engineering, Beijing University of Technology, 2009.

[14] K. Fitzpatrick, P. Carlson, M. Brewer, and M. D. Wooldridge, "Design speed, operating speed, and posted speed limit practice," in Proceedings of the 82nd Annual Meeting Transportation Research Board, 2003.

[15] J. Hu and J. Wang, "Safety evaluation of freeway horizontal curve based on driver workload," Journal of Transportation Systems Engineering and Information, vol. 12, no. 1, pp. 31-37, 2012.

[16] M. A. Brewer, G. Pesti, and W. Schneider, "Improving compliance with work zone speed limits: effectiveness of selected devices," Transportation Research Record: Journal of the Transportation Research Board, no. 1948, pp. 67-76, 2006.

[17] G. Kanellaidis, "Human factors in highway geometric design," Journal of Transportation Engineering, vol. 122, no. 1, pp. 59-66, 1996.

[18] L. -M. Wang, V. G. Duffy, and Y. Du, "A composite measure for the evaluation of mental workload," in Digital Human Modeling, pp. 460-466, 2007.

[19] J. Lee and S. Lee, "Development of model for highway design consistency evaluation with artificial neural network," in Proceedings of the 13th International conference on Multimedia Modeling (MMM '07), vol. 4352, Part II, pp. 620-626, Lecture Notes in Computer Science, 2007. 


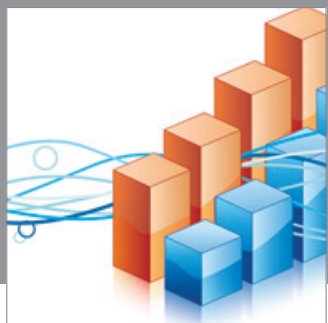

Advances in

Operations Research

mansans

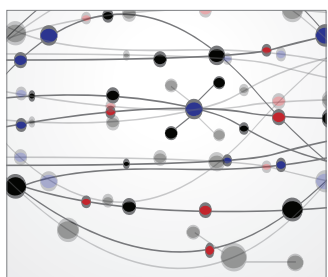

The Scientific World Journal
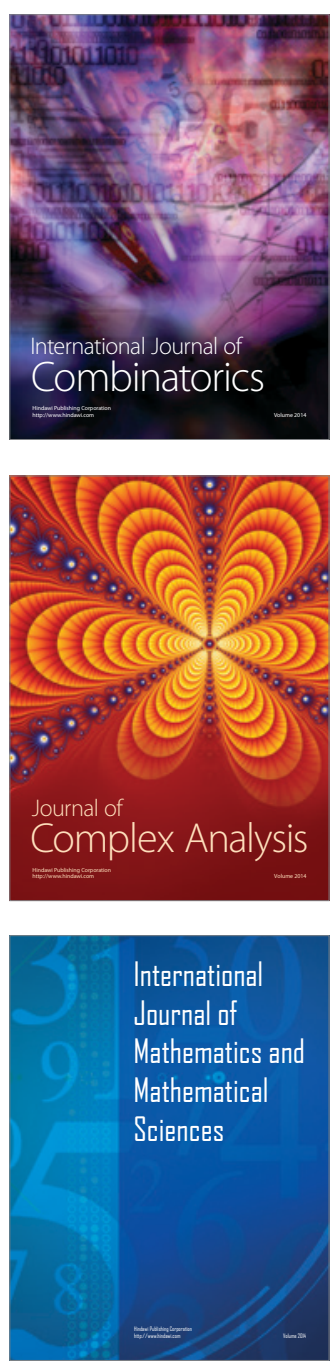
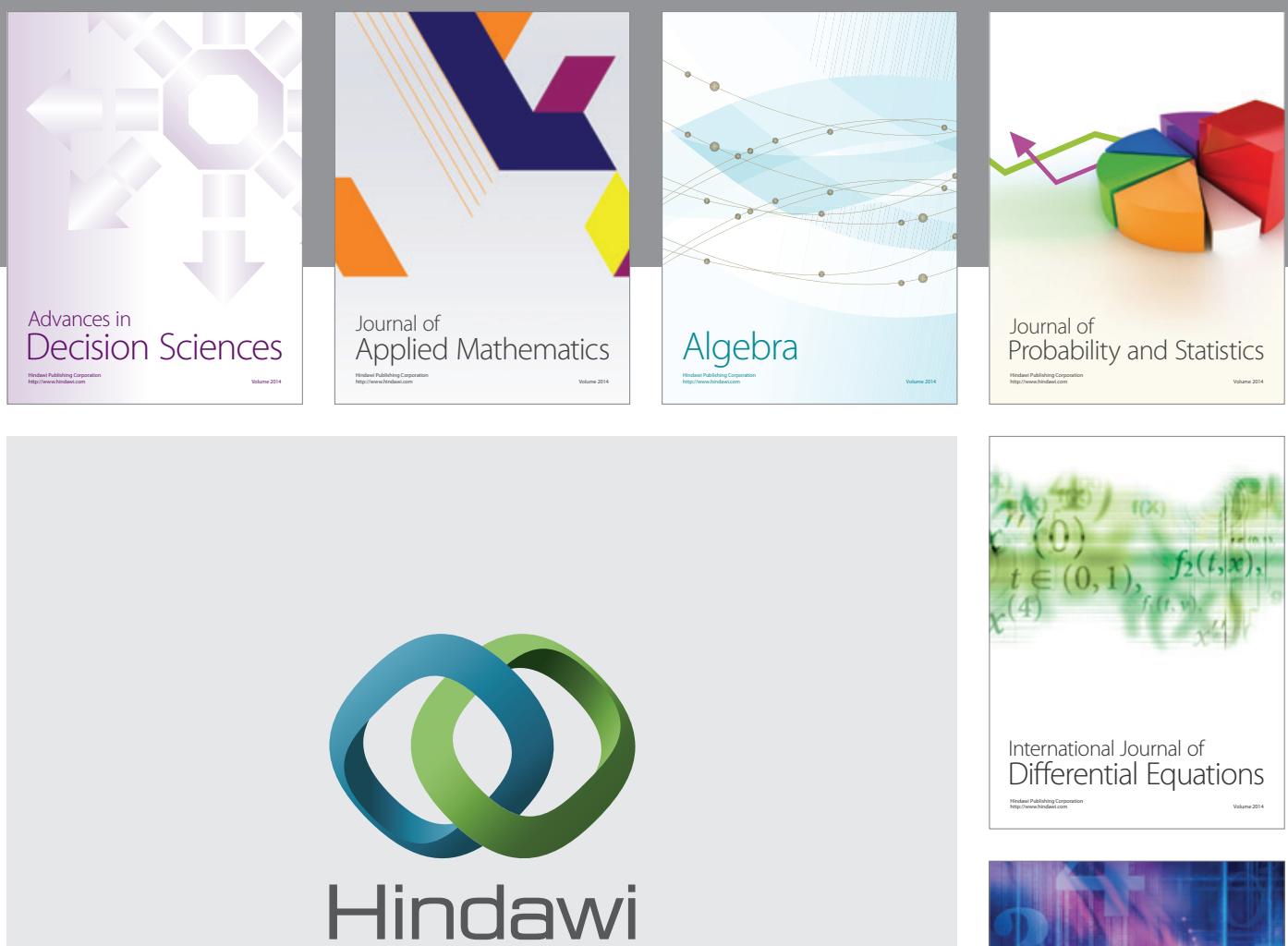

Submit your manuscripts at http://www.hindawi.com
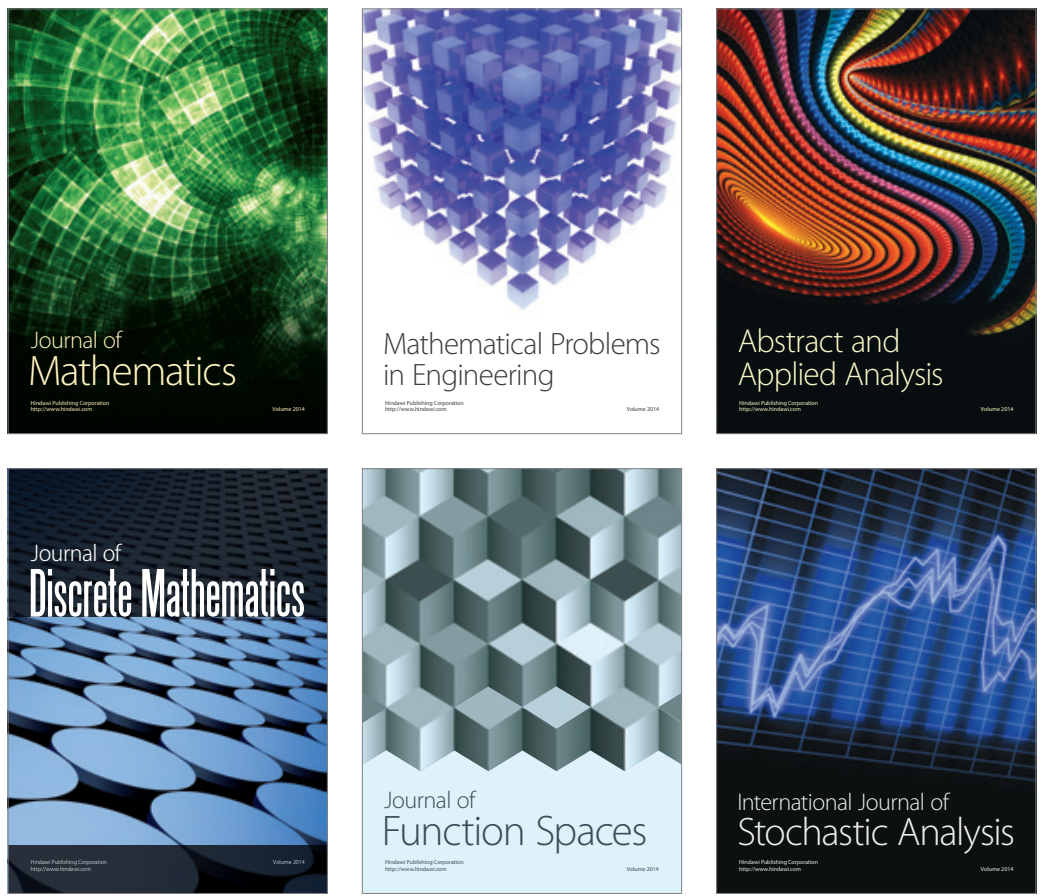

Journal of

Function Spaces

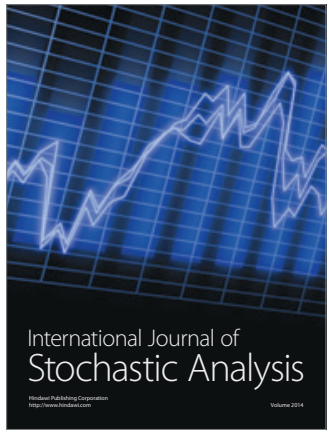

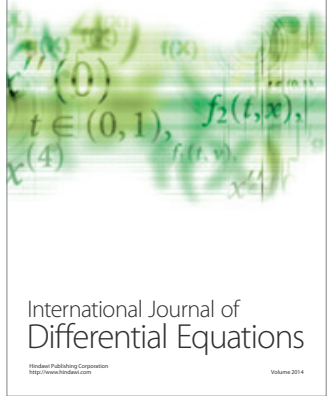
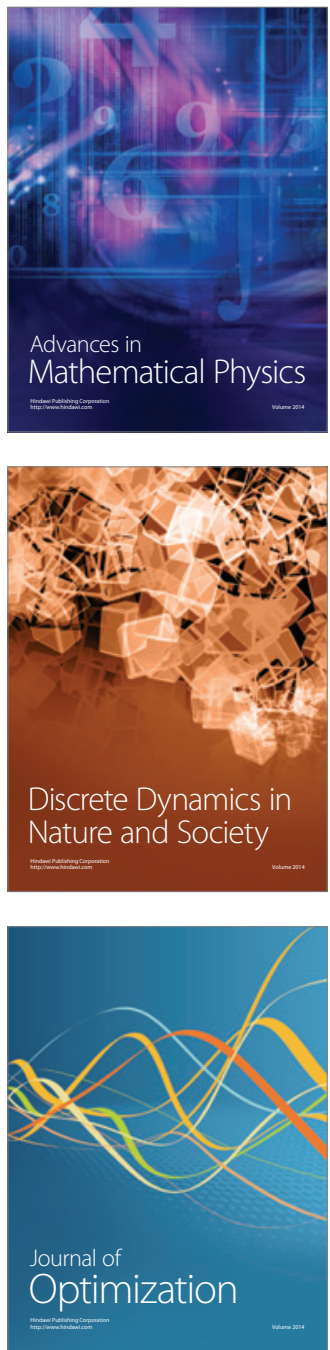